\section{A comunicação médico-paciente na percepção de mulheres com nódulo mamário e indicação de biópsia}

\section{Doctor-patient communication as perceived by women with a mammary nodule recommended for biopsy}

\begin{abstract}
Objectives: to understand how communication with mastologists is perceived and interpreted on diagnosis of a mammary nodule recommended for biopsy.

Methods: a qualitative, hermeneutical and critical, study was carried out at a referral center in Recife, in the Brazilian State of Pernambuco. Semistructured interviews were conducted with 16 women aged between 35 and 63 years. Two groups of women were formed (Group 1 with a possible cancer diagnosis and Group 2 without).

Results: no woman reported any interest on the part of the physician in her perception of the disease. The relation with the mastologists was satisfactory for Group 1, especially in terms of sincerity and solidarity in providing access to consults and examinations. In Group 2, the perception of a lack of reciprocity was predominant. Doctor-patient communication succeeded principally when there was a need for the health worker to meet scientifically recognized requirements and provide information, with more time being taken and more clarification given with Group 1. The trivialization of a benign nodule by the physician resulted in enormous dissatisfaction among women in Group 2 in terms of information obtained, in particular in the diagnosis and course of action to be taken. Generally speaking, the patient's right to express an opinion regarding their degree of comfort was disregarded.

Conclusions: doctor-patient communication is informative and paternalistic in nature, with greater attention being given to women suspected to have cancer. None of them, even where very dissatisfied, aimed at an individual treatment project. Dialogue is difficult for doctors and patients.
\end{abstract}

Key words Breast, Breast neoplasms, Health communication, Comprehensive health care
Ana Clara Araújo Miranda 1

Katia Virginia de Oliveira Feliciano 2

Marisa Amorim Sampaio 3

1-3 Instituto de Medicina Integral Prof. Fernando Figueira. Rua dos Coelhos, 300. Boa Vista. Recife, PE, Brasil. CEP. 50.070-550.

E-mail: acamiranda@hotmail.com

Resumo

Objetivos: compreender como a comunicação com mastologistas é percebida e interpretada no diagnóstico de nódulo mamário com indicação de biópsia.

Métodos: estudo qualitativo, com abordagem hermenêutica e crítica, efetuado em serviço de referência, em Recife, PE. Foram realizadas entrevistas semiestruturada com 16 mulheres entre 35-63 anos de idade. Formaram-se dois grupos de mulheres (Grupo 1 com e Grupo 2 sem hipótese diagnóstica de câncer).

Resultados: nenhuma mulher relatou interesse do médico por sua percepção da doença. A relação com mastologistas foi satisfatória para o Grupo 1, sobretudo, pela sinceridade e atitude solidária ao facilitar o acesso a consultas e exames. No Grupo2 predominou a percepção de falta de reciprocidade. A comunicação médico-paciente sucedeu, principalmente, enquanto era necessária ao profissional, para apreender demandas reconhecidas cientificamente $e$ fornecer informações, sendo mais demorada $e$ esclarecedora com o Grupo 1. A banalização do nódulo benigno pelo médico resultou numa enorme insatisfação das mulheres do Grupo 2 quanto às informações obtidas, em particular, na definição do diagnóstico e conduta. Em geral, desconsiderou-se direito da paciente de opinar sobre suas conveniências.

Conclusões: a comunicação médico-paciente teve caráter informativo e paternalista, com maior atenção dedicada às mulheres com suspeita de câncer. Nenhuma delas, ainda quando muito insatisfeitas, visaram de fato um projeto terapêtico individual. Dialogar é tarefa difícil para médicos e pacientes.

Palavras-chave Mama, Neoplasias da mama, Comunicação em saúde, Assistência integral à saúde 


\section{Introdução}

O câncer de mama é o segundo tipo de neoplasia maligna mais frequente no mundo. No Brasil, em 2012, estimou-se que ocorreriam ao redor de $53 \mathrm{mil}$ novos casos da doença, ${ }^{1}$ representando quase $20 \%$ dos nódulos diagnosticados com indicação de biópsia. ${ }^{2}$ A trajetória diagnóstica do nódulo de mama desperta temores e expectativas acerca do câncer, 3,4 ressaltando a essencialidade do diálogo para assistência qualificada. ${ }^{5-7} \mathrm{~A}$ ênfase atual na medicina baseada em evidências e no atendimento protocolizado torna a prática médica despreparada para o desafio de associar excelência técnica com comunicação voltada à presença do outro no espaço assistencial. 5

O modelo biomédico de atenção prioriza o conhecimento técnico-científico sobre a doença, em detrimento da subjetividade e intersubjetividade de interpretações do adoecer, valoriza apenas os relatos objetivos da enfermidade e o aportado pelo médico ao paciente, instituindo e reproduzindo relações sistematicamente assimétricas.5,8,9 Para Thompson, 10 as trajetórias vividas e as posições ocupadas por indivíduos e instituições relacionam-se aos recursos simbólicos (prestígio e reconhecimento) e culturais (conhecimentos e habilidades) acumulados. A capacidade de buscar o alcance de objetivos depende do lugar ocupado num dado contexto de interação, permitindo falar de indivíduos ou grupos "dominantes" e "subordinados".

O foco na dimensão técnica da atenção favorece o desenvolvimento do modelo paternalista de comunicação, no qual o paciente é pouco informado e quase não participa das decisões relacionadas à sua doença, dependendo do julgamento e ideias do profissional. 7 Igualmente favorece o modelo informativo referido ao direito do paciente de receber informações sobre diagnóstico e prognóstico para decidir sobre a realização do tratamento.7,11 O segundo modelo, que atualmente é o mais utilizado, pretende problematizar o poder do médico sobre o paciente, remetendo à capacidade de efetuar a melhor escolha dentre alternativas baseadas num saber científico. Todavia, persiste a subordinação ao ponto de vista do profissional que deve persuadir o paciente sobre a eficácia de intervenções, raramente buscando se colocar em acordo dialógico com o outro. ${ }^{12}$

A comunicação médico-paciente é associada à resposta emocional ao adoecimento, aos níveis de adesão à terapêutica e à satisfação do paciente e do profissional.1,13-15 As pesquisas sobre o tema, junto aos doentes de câncer, voltam-se aos aspectos valorizados pelos pacientes ao receber más notícias: contexto e modo de comunicar prognóstico, conteúdo e quantidade de informação e suporte psicológico. 16,17

Os resultados acerca da comunicação informativa tanto mostram que os pacientes desejam receber mais informações do que as que foram dadas e participar da decisão sobre tratamento, como evidenciam que podem fazer poucas perguntas, falar pouco sobre si mesmo e não desejar participar das decisões. ${ }^{13,14,18}$ Os pacientes mais jovens, do gênero feminino e com maior escolaridade expressam mais o desejo de receber informações detalhadas e apoio emocional. 16

Nas doenças da mama, o olhar sobre a comunicação médico-paciente está focado na informação do prognóstico e tratamento dos casos malignos.13,17,18 Wright et al.14 identificam entre mulheres com câncer de mama, que responder sem hesitação aos questionamentos feitos, com sinceridade e reconhecimento da sua singularidade, são elementos centrais para estabelecer relação de confiança com o médico. Para estes autores, é essencial considerar a perspectiva dessas mulheres sobre provisão de informações e possibilidades de escolha, para contemplar as necessidades e não o que os profissionais pensam que são as necessidades delas.

Em reflexões teóricas sobre a comunicação reconhece-se a importância de práticas dialógicas que propiciem relações mais equânimes, confiança, respeito mútuo e colaboração, resultando num atendimento mais compreensivo e resolutivo. $5,15,17$ Para Gadamer, 19 as condições de diálogo decorrem dos papéis atribuídos aos interlocutores, resultantes do entrelaçamento entre linguagem e poder, havendo diálogo apenas quando ocorre uma troca recíproca de perguntas e respostas. A comunicação dialógica caracteriza o modelo comunicacional, no qual a conversa é a substância do trabalho em saúde, remetendo à singularidade de cada encontro médicopaciente. 6,20

Num contexto onde há um crescimento do acesso ao diagnóstico das doenças mamárias e no qual a humanização das práticas de saúde confere particular importância à comunicação profissionalusuário, buscou-se compreender como as mulheres percebem e interpretam a comunicação com mastologistas, no processo diagnóstico de nódulo mamário com indicação de biópsia.

\section{Métodos}

Efetuou-se estudo qualitativo em hospital-escola de interesse público, de referência para atenção à saúde 
da mulher, em Recife, Pernambuco, de novembro de 2009 a setembro de 2010. No setor de ultrassom, obteve-se amostra de conveniência constituída por 16 mulheres com idade entre 35-65 anos, grupo etário da descoberta da maioria dos nódulos, ${ }^{2}$ encaminhadas pelos quatro mastologistas do serviço para realizar biópsia de nódulo mamário guiada por ultrassonografia. Definiu-se o tamanho da amostra por saturação, após avaliar que reincidência e complementaridade das informações permitiam delinear o quadro empírico da investigação, sendo suficiente para conformar dois grupos na análise e sugerir conclusões. ${ }^{21}$ Houve duas recusas e duas exclusões por falta de condições cognitivas e emocionais para colaborar.

Nos prontuários das pacientes foram obtidas informações acerca da condição clínica e diagnóstico. As entrevistas semiestruturadas, gravadas e transcritas na íntegra, foram realizadas por uma das pesquisadoras, em sala da biblioteca da instituição, preservando confidencialidade da informação. Efetuaram-se no mínimo três sessões (após solicitação de biópsia, realização do exame e comunicação do resultado) para explorar roteiro: identidade social, percepções do nódulo mamário, comunicação médico-paciente e significados e sentimentos acerca da mama. Cada entrevistada produziu em média 2h34min de gravação. Para assegurar anonimato, os relatos foram codificados com a letra "M" - sem hipótese diagnóstica de câncer mamário; "Mhd" com hipótese diagnóstica e "Mc" - hipótese confirmada, seguida do número atribuído à mulher.

A abordagem hermenêutica 22 e crítica 10 foram adotadas na busca por uma compreensão fundada no caráter histórico-social da comunicação médicopaciente. Para Gadamer22: a) o significado é negociado no ato da interpretação, logo, a compreensão não é algo reproduzido por um intérprete mediante análise de um texto que ele procura compreender; b) interpretar significa ir mais além dos fenômenos e dados manifestos; c) o intérprete reflete sobre preconceitos herdados historicamente e mantidos de modo irrefletido para mudar aqueles que comprometem o esforço de compreensão do outro e de si mesmo.

Da perspectiva crítica toda reflexão parte da constatação das maneiras complexas como o significado é mobilizado para manter relações de dominação. Para Thompson, 10 as formas simbólicas estão situadas em campos de interação, constituídos como espaço de posições e conjunto de trajetórias que simultaneamente condicionam as relações entre pessoas e as oportunidades acessíveis a elas. Analisar as instituições sociais, que dão uma forma particular aos campos de interação, é reconstruir regras, recursos e relações, examinando as práticas e atitudes das pessoas que agem dentro dela, para identificar as assimetrias e diferenças e as possibilidades de sua transformação.

A análise, balizada no referencial teórico da comunicação médico-paciente, abrangeu: a) leitura compreensiva para apreender o "todo" de cada relato e visualizar o conjunto dos discursos; b) identificação e recorte temático dos relatos sobre comunicação médico-paciente; c) identificação dos modos de pensar e sentir das mulheres, dos argumentos e contradições presentes no discurso; d) interpretação mediante questionamento pelas três pesquisadoras de ideias e sentimentos das entrevistadas sobre as vivências nas consultas, aprofundando o diálogo entre dimensão subjetiva e contextual, para elucidar significados implícitos. As áreas temáticas desenvolvidas a partir dos relatos foram: a) processo relacional médico-paciente, incluindo as categorias "dispensar atenção" e "atitude solidária"; b) configurações das práticas comunicativas, contendo o "predomínio da conversa tecnocrática" e a "decisão unilateral".

No processo sequencial de interpretação, iniciado no trabalho de campo, delineou-se nos discursos das mulheres a diferenciação dos atributos da consulta quando o médico suspeitava ou não da malignidade do nódulo. Para problematizar as possíveis repercussões da presunção de câncer na comunicação médico-paciente, formaram-se dois grupos: Grupo 1: mulheres com hipótese diagnóstica de câncer mamário; e Grupo 2: sem hipótese diagnóstica de câncer.

O Termo de Consentimento Livre e Esclarecido foi obtido de todas as mulheres. O projeto foi aprovado pelo Comitê de Ética em Pesquisa do Instituto de Medicina Integral Prof. Fernando Figueira, com o no 1579 em 23/11/2009.

\section{Resultados e Discussão}

O Grupo 1 compunha-se de seis mulheres entre 3763 anos de idade. Duas tinham história prévia de nódulo benigno. Na trajetória presente, consultaramse com um a três mastologistas, frequentemente em serviços públicos, efetuando de duas a seis consultas. Uma utilizou apenas o hospital-escola campo desta pesquisa.

O Grupo 2 constava de dez mulheres entre 35-57 anos de idade. Cinco submeteram-se à cirurgia de nódulo benigno. Na história atual, consultaram-se com um a quatro mastologistas, geralmente em serviços públicos, realizando de uma a cinco 
consultas (paciente com trajetória mais longa não quantificou consultas). Cinco utilizaram apenas o hospital-escola. Uma mulher grávida seria reavaliada após o parto, pois o nódulo identificado antes da gravidez não foi visto à pré-punção realizada no período gravídico.

As características das entrevistadas encontramse na Tabela 1.

Tabela 1

Características sociodemográficas, antecedentes de nódulo e história do processo diagnóstico atual das mulheres. Recife, Pernambuco, 2010.

\begin{tabular}{|c|c|c|c|c|c|c|c|}
\hline \multirow[b]{2}{*}{ Idade } & \multirow[b]{2}{*}{ Escolaridade } & \multicolumn{3}{|c|}{ História prévia } & \multicolumn{3}{|c|}{ História atual } \\
\hline & & $\begin{array}{l}\text { Nódulo } \\
\text { benigno }\end{array}$ & Cirurgia & $\begin{array}{l}\text { Suspeita de } \\
\text { câncer }\end{array}$ & $\begin{array}{c}\text { Mastologistas } \\
\text { consultados }\end{array}$ & $\begin{array}{c}\text { Número de } \\
\text { consultas }\end{array}$ & Diagnóstico \\
\hline 37 & $\begin{array}{l}2^{a} \text { série (ensino } \\
\text { fundamental) }\end{array}$ & Sim & Sim & Sim & Dois & Três & Benigno \\
\hline 50 & $\begin{array}{l}\text { Ensino médio } \\
\text { completo }\end{array}$ & Não & Não & Sim & Dois & Quatro & Benigno \\
\hline 56 & $\begin{array}{l}\text { Fundamental } \\
\text { completo }\end{array}$ & Não & Não & Sim & Um & Duas & $\begin{array}{c}\text { Maligno } \\
\text { (metástase) }\end{array}$ \\
\hline 63 & $\begin{array}{l}3^{a} \text { série (ensino } \\
\text { fundamental) }\end{array}$ & Sim & Não & Sim & Dois & Cinco & Maligno \\
\hline 56 & $\begin{array}{l}\text { Ensino médio } \\
\text { completo }\end{array}$ & Não & Não & Sim & Dois & Seis & $\begin{array}{c}\text { Maligno } \\
\text { (metástase) }\end{array}$ \\
\hline 58 & $\begin{array}{l}5^{a} \text { série (ensino } \\
\text { fundamental) }\end{array}$ & Não & Não & Sim & Três & Seis & $\begin{array}{c}\text { Maligno } \\
\text { (metástase) }\end{array}$ \\
\hline 47 & $\begin{array}{l}\text { Superior } \\
\text { completo }\end{array}$ & Sim & Sim & Não & Quatro & $\begin{array}{l}\text { Não soube } \\
\text { especificar }\end{array}$ & Benigno \\
\hline 53 & $\begin{array}{l}\text { Ensino médio } \\
\text { completo }\end{array}$ & Não & Não & Não & Um & Duas & Benigno \\
\hline 35 & $\begin{array}{l}\text { Superior } \\
\text { completo }\end{array}$ & Sim & Sim & Não & Dois & Três & $\begin{array}{l}\text { Reavaliação } \\
\text { após o parto }\end{array}$ \\
\hline 40 & $\begin{array}{l}\text { Ensino médio } \\
\text { completo }\end{array}$ & Não & Não & Não & Dois & Cinco & Benigno \\
\hline 41 & $\begin{array}{l}6^{a} \text { série (ensino } \\
\text { fundamental) }\end{array}$ & Sim & Sim & Não & Dois & Cinco & Benigno \\
\hline 57 & $\begin{array}{l}3^{a} \text { série (ensino } \\
\text { fundamental) }\end{array}$ & Sim & Sim & Não & Um & Três & Benigno \\
\hline 39 & $\begin{array}{l}7^{a} \text { série (ensino } \\
\text { fundamental) }\end{array}$ & Não & Não & Não & Um & Três & Benigno \\
\hline 45 & $\begin{array}{l}\text { Superior } \\
\text { completo }\end{array}$ & Não & Não & Não & Dois & Três & Benigno \\
\hline 42 & $\begin{array}{l}4^{a} \text { série (ensino } \\
\text { fundamental) }\end{array}$ & Não & Não & Não & Um & Duas & Benigno \\
\hline 37 & $\begin{array}{l}\text { Ensino médio } \\
\text { completo }\end{array}$ & Sim & Sim & Não & Um & Duas & Benigno \\
\hline
\end{tabular}




\section{Processo relacional médico-paciente}

Num contexto onde o modelo da biomedicina desvaloriza a subjetividade do processo saúdedoença-atenção, as distintas correntes teóricas que abordam a relação entre conhecimento e prática, reconhecendo a diversidade de perspectivas e sentimentos que orientam a ação humana, compartilham a ideia de que é essencial superar a cisão entre doença e doente. $7,8,11,23$ Para Gadamer, ${ }^{19}$ o encontro médico-paciente coloca o enorme desafio de, na aplicação do saber técnico-científico, reconhecer no outro o seu ser-diferente, buscando orientar as decisões com base, também, nos distintos modos de pensar, sentir e agir.

Neste estudo, as mulheres destacaram dois aspectos na definição da maneira de relacionar-se com os mastologistas:

a) Dispensar atenção: em geral, remeteram-se ao modo como foram tratadas na consulta, a partir de elementos que suscitaram satisfação ou insatisfação com o atendimento, afetando a confiança técnica: formular perguntas adequadas/inadequadas; efetuar exame físico minucioso/superficial; avaliar e solicitar exames. Igualmente a confiança relacional: ser educado/indelicado; deixar à vontade/constranger; mostrar-se atento/desatento; demonstrar simpatia/ antipatia; ser paciente/impaciente; ser sincero/não revelar e proporcionar/não proporcionar espaço de expressão. A percepção de pressa ao atender, presente principalmente no Grupo 2, levou a reprovar a atitude do profissional.

“[...] ele conversou pouco comigo, cinco segundos, não perguntou se eu tava bem, nem se tava mal, foi escrevendo lá as coisas que ele mesmo sabe" (M14).

"Perguntou tudo, ele presta muita atenção ao que a gente fala. A gente sente confiança com um médico que realmente para pra escutar, pra examinar, prestar atenção no que tá fazendo" (Mc16).

A receptividade à entrada, ressaltada na primeira consulta, comumente foi avaliada mediante comunicação não verbal: "sorriu pra mim, me encarou mesmo assim nos olhos, eu disse, é dessa que eu gosto" (Mc9) ou "ela é séria, meio fechada, ai eu licença doutora - ela não deixa a gente tão à vontade" (M1), a qual tem grande importância no relacionamento e compreensão mútua. ${ }^{24}$ A primeira impressão, supervalorizada nos relatos das mulheres, segundo Diaz, 17 propicia a construção dos contextos da relação médico-paciente no primeiro encontro, afetando decisivamente a confiança e o vínculo necessários ao diagnóstico e tratamento. A entrada no consultório foi sempre importante: "a última vez eu dei boa tarde e ele me respondeu, mas não olhou pra mim" (M15). Elas compreendiam que a disponibilidade em atender era identificada "pela forma como ele (o médico) recebe" (M4).

As aspirações nas relações interpessoais estavam direcionadas ao atendimento por um médico "que converse com a gente, que pergunte o que a gente tem, que a gente tenha a liberdade de falar" (Mhd2). Todavia, as experiências prévias, particularmente no Grupo 1, reduziam as expectativas: "Não me tratando com ignorância, com cara feia, com estupidez, me tratando bem, sorridente, pra mim tá bem demais" (Mc9). A desconsideração das próprias demandas e significados leva à reflexão de Teixeira 20 sobre as nossas necessidades não nos serem sempre imediatamente transparentes. Ademais sugere que pensamentos e percepções estão estruturados em concordância com a unilateralidade das decisões tomadas pelo médico. ${ }^{9,11}$

Poucas mulheres, quase sempre do Grupo 2, com maior escolaridade, expressaram a necessidade da escuta de medos e ansiedades geradas pelo nódulo. Estas, sobretudo, admitiam o distanciamento emocional do médico como inerente à prática profissional, mas manifestaram o desejo de compreensão da singularidade do doente, para motivar uma maior colaboração dele no processo diagnóstico e terapêutico. Ao requerer que o profissional considerasse a adequação do julgamento e decisões assistenciais, para dado caso e contexto, questionavam a objetividade e a assimetria da comunicação médico-paciente sustentada pela biomedicina. 8,9

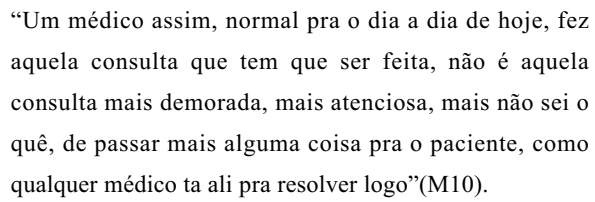

b) Atitude solidária: a percepção da existência ou inexistência de interesse e compromisso do médico frente ao seu problema permitiu sentir-se (ou não) emocionalmente apoiada. Comumente foram as mulheres do Grupo 1 que referiram, com gratidão, a solicitude do profissional ao facilitar o acesso a consultas e exames, bem como ao expressar a disponibilidade de ajuda, propiciando confiança e reduzindo o sentimento de isolamento. $\mathrm{Na}$ opinião delas, a atitude de cuidado extrapolava as atribuições do médico, reforçando as baixas expectativas relacionadas à atenção desse profissional. 
"[...] ela disse que eu não me preocupasse - o que eu puder fazer pra lhe ajudar, eu vou fazer... você não está sozinha - eu agradeci" (Mhd5).

"E foi até ainda mais, foi lá onde faz as fichas, comigo, de tão legal que ela é, viu? Falou com a menina - olhe, ajeita aí pra fazer o exame dela" (Mc9).

Essa solicitude foi mais associada aos mastologistas que definiram o diagnóstico, geralmente profissionais do hospital-escola cujo protocolo preconizava rapidez para diagnosticar casos suspeitos de malignidade. Portanto, na aplicação dos resultados desta pesquisa convém, também, considerar que a organização do processo de trabalho pode ter favorecido a supervalorização do apoio recebido do médico pelas mulheres do Grupo 1 .

Nos relatos das vivências das pacientes do Grupo 2 predominou a percepção de falta de reciprocidade, que levou ao julgamento de que o seu caso não recebera a devida atenção. Algumas atribuíram à benignidade do nódulo, o que definiram como desinteresse do profissional. Schraiber 23 lembra as tensões na relação médico-paciente decorrentes das diferenças na valorização do adoecimento, uma vez que tomar doentes por doenças é um aspecto comum na intervenção médica. Nesse grupo, poucas mulheres falaram da influência positiva do apoio emocional do médico sobre o modo de lidar com a doença.

\footnotetext{
"Tem que conversar com a paciente, olhar pra ela, dá atenção.[...] teve uma hora que ele deixou as médicas (acadêmicas) me examinando, por tabela ele fez - diga a essa senhora que ela não tem nada, pra parar de botar na cabeça que tem alguma coisa" (M14)
}

Os depoimentos apontaram mudanças na interação médico-paciente ao longo das consultas, configurando contextos diferenciados. $\mathrm{O}$ ato médico é sempre uma intervenção duplamente particular, pois incide em cada pessoa, a cada vez. ${ }^{23}$ Assim, as mulheres do Grupo 1 foram fortalecendo a confiança e a maioria do Grupo 2 aumentou o sentimento de estar pouco à vontade com o mastologista, dizendo ter recebido menos atenção no último contato, quando da comunicação do resultado da biópsia e prescrição da conduta. A interação com um mesmo profissional suscitou percepções distintas em diferentes pacientes, o que reitera a importância da situação da consulta para comunicação médicopaciente. 25

A presunção de malignidade propiciou à paciente uma percepção de tratamento diferenciado, mas não motivou um contato compreensivo no sentido de atravessar a divisão entre o saber genérico do conhecimento teórico e a situação singular do doente. ${ }^{19}$ Como identificado por Schraiber ${ }^{23}$ na relação médico-paciente noutro contexto, pode-se dizer que o mastologista apreendeu a doente individual por sua pertença (ou não) ao coletivo de casos suspeitos, atributo que fundamentou o padrão e a rotina de atendimento. $\mathrm{O}$ menoscabo pelas interpretações da doença e modos de agir,7,20 dificulta a conciliação de necessidades, interesses e desejos. ${ }^{5}$

\section{Configurações das práticas comunicativas}

Nesta pesquisa, a comunicação médico-paciente sucedia, sobretudo, enquanto era necessária ao profissional, para apreender demandas reconhecidas cientificamente. Num contexto comunicativo que denotava ação do médico sobre a paciente, característica que para Schraiber ${ }^{9}$ traduz assimetria cujos elementos estruturais se repetem na assistência médica, dois elementos se destacaram:

a) A conversa tecnocrática: segundo os relatos, a comunicação mulher-profissional teve caráter técnico: anamnese, informações consideradas necessárias pelo médico (características do nódulo, diagnóstico, prognóstico e tratamento), comumente sem interrogar sobre as necessidades percebidas pela paciente, cuja visão parecia não despertar interesse. Os relatos sinalizaram para uma comunicação mais flexível com as pacientes do Grupo 1, com predomínio de conversa mais prolongada: anamnese e exame físico detalhado (no hospital-escola, essas pacientes foram examinadas em quase todas as consultas), informações mais particularizadas e abrangentes (procedimento da biópsia, alternativas terapêuticas), esclarecendo mais as dúvidas. As pacientes desse grupo não foram estimuladas, mas encontraram espaço para expressão pontual de sentimentos.

A hipótese diagnóstica de câncer comumente foi informada na primeira consulta com mastologista que definiu o diagnóstico. Esta atitude é característica da estratégia realista, na qual o médico conta a verdade ao doente sobre a gravidade da doença, partindo do princípio de que ele necessita saber, sem considerar o desejo dele de ser informado. $18 \mathrm{~A}$ maioria das mulheres do Grupo 1 interrogou sobre malignidade do nódulo e solicitou esclarecimentos. Apesar do impacto provocado pela notícia: "Eu fiquei abalada, confesso que fiquei" (Mhd5), todas valorizaram a sinceridade do profissional: "ela foi positiva... ela falou a verdade" (Mc9), pois, segundo afirmaram, isso evitou que fossem pegas de surpresa. A sinceridade representava um dos aspectos centrais 
para estabelecer relação de confiança com o médico, semelhante às mulheres com câncer de mama estudadas por Wright et al. ${ }^{14}$

Contudo, como noutras pesquisas, ${ }^{14,18}$ pacientes com doença avançada evitavam questões cujas respostas tocavam os temores mais profundos associados ao câncer de mama: "se era pra tirar a mama, se era pra tirar só o nódulo, mas só que... eu esqueci" (Mc12) e "até eu queria perguntar, mas acho que não vão dizer qual o tempo de vida que eu posso ter" (Mc3). É importante conhecer prognóstico e tratamento, mas, ao renovar a compreensão da variabilidade dos casos, a complexidade do processo e a singularidade dos afetos envolvidos, estes depoimentos fortalecem as críticas ao "realismo" que pode ser percebido como agressivo e exacerbar reações emocionais. 17,18

A importância do diálogo está relacionada ao vínculo e à corresponsabilidade. $\mathrm{O}$ vínculo pode favorecer uma aproximação ao valor que o adoecimento e as práticas em saúde têm para os sujeitos, sendo a verdadeira fonte de responsabilidade mútua. $\mathrm{O}$ vínculo e a corresponsabilidade possibilitam, na relação médico-paciente, a construção da autonomia, reconhecendo-se que ambos os sujeitos necessitam ter espaço e voz nos processos de decisão. 5,26,27

No Grupo 2, embora buscassem informações (características do nódulo, razões do aparecimento, malignidade e biópsia), as pacientes tenderam a silenciar as dúvidas, por razões como dificuldade na interação com médico, timidez, presença de acadêmicos e percepção de que o profissional preocupava-se com o tempo. Expressaram mais seus temores, sobretudo quando a solicitação de biópsia escamoteou o alívio da presunção de benignidade do nódulo: "eu fiquei um pouco arrasada, no fundo a gente entristece" (M10). Os discursos indicaram a propensão dos profissionais para trivializar as preocupações das pacientes, sugerindo dificuldades de lidar com a complexidade das vivências do adoecimento.

"Biópsia? Vai cortar meu seio? A senhora tá suspeitando de câncer? [...] é benigno, não se preocupe não, não se precipite, não seja peru pra morrer de véspera - como ela falou né?" (M1).

O processo diagnóstico do nódulo mamário é atravessado pela percepção do risco de câncer com a imagem de sofrimento e morte. A indicação de biopsia desperta ou acentua medos e antevisão de más notícias. ${ }^{28}$ A mama tem forte carga simbólica e o câncer de mama pode afetar a identidade feminina.3,4 $\mathrm{O}$ temor da mastectomia amplamente difundido no estudo atual provocou angústia.

"[...] isso que me traz medo né, que é uma coisa muito... assim, constrangedora pra mulher, eu não aceito, eu fico no pensamento - meu Deus deve ser como uma mulher sem o seio? - não consigo aceitar" (M14).

Para Caprara e Franco, ${ }^{7}$ a atitude do médico de valorizar apenas o que é aportado pelo conhecimento técnico nutre a incompreensão dele pela linguagem do paciente ao expressar o seu padecer. A desconsideração pelas concepções da paciente limita a busca sistemática de necessidades mais silenciosas no contexto de cada encontro médico-paciente. 5,17,20 Um entendimento maior das necessidades implica no reconhecimento de que a construção do significado do adoecer é um processo histórico-social, mas cada vivência do adoecimento é única.13,17,18

Independentemente da hipótese diagnóstica de câncer, nenhuma mulher relatou interesse do médico por seu contexto de vida, tampouco por sua interpretação do adoecimento. Numa vivência generalizada de temor da malignidade, esta atitude repercutiu negativamente na acolhida do sofrimento. Elucidado no contraditório: "a gente só pensa no ruim, um ruim confiante, mas a gente só pensa no ruim" (M10); no desassossego: "estou bastante nervosa, um medo, um medo assim... ai fico com aquilo na cabeça" (M13); na negação: "eu sei que é uma coisa ruim, mas eu não botei na minha cabeça que é ruim" (Mc9) e na impotência: "eu coloquei minha vida na mão de Deus" (M8).

O diagnóstico foi finalizado no hospital-escola, sendo comum a paciente não ser o foco da comunicação devido à presença de acadêmicos. Porém, para algumas mulheres do Grupo 2 a falta de privacidade suscitou constrangimento: "eu fiquei um pouco envergonhada porque tinha dois estudantes, morta de vergonha" (M8). Existindo ou não a presunção de malignidade, a conversa paralela entre médico e estudante que propiciou informações indiretas, muitas vezes ininteligíveis pela linguagem técnica, produziu ansiedade acentuando a insegurança: "elas ficaram lá conversando... não to entendendo nada, meu Deus, será que aquele negócio é perigoso mesmo, será?" (Mc9). Houve circunstâncias em que faltou clareza às explicações sobre diagnóstico e tratamento, sendo raramente verificada a compreensão da paciente.

Dentre os portadores de neoplasias, são as mulheres com câncer de mama que recebem menos informações relevantes para saúde e se mostram mais insatisfeitos com a informação dada por seus provedores.16 $\mathrm{Na}$ pesquisa atual, a distinta valorização da enfermidade por médicos e pacientes 
resultou numa enorme insatisfação das mulheres com doença benigna quanto às informações obtidas, em especial, na definição do diagnóstico e conduta. No Grupo 1, poucas vezes ficaram insatisfeitas com as informações dadas, mostrando-se particularmente satisfeitas com aquelas recebidas ao finalizar o processo diagnóstico. Como noutros estudos, 11,14 as informações fornecidas as mulheres desse grupo foram ainda mais satisfatórias quando corresponderam às expectativas de boas notícias (controle da dor, possibilidade de vida normal, benignidade).

b) O predomínio da decisão unilateral: os depoimentos das mulheres revelaram que, afora uma paciente do Grupo 2 interrogada sobre a vontade de ser operada e que deixou a profissional decidir, foi feita indicação terapêutica com alguns esclarecimentos, mas sem negociação. Este modo de agir se contrapõe à crescente importância atribuída, nos Estados Unidos e na Europa, à assinatura pelo paciente do consentimento livre e informado, que se tornou num complemento indissociável da matriz informativa, visando aumentar a segurança do acesso à assistência qualificada. Sobretudo nas situações em que compete esclarecer acerca dos riscos e benefícios de procedimentos e tratamentos invasivos, 29 como pode ocorrer no câncer de mama. Esta assinatura também protege o médico frente à possibilidade recorrente de indiciamento judicial. No Brasil, desde outubro de 2010, o Código de Ética Médica legisla sobre a obrigatoriedade do médico em garantir ao paciente o direito à livre decisão sobre sua pessoa. 30

Há uma tensão constante na prática médica advinda do conflito entre os princípios da autonomia e a preocupação com o que mais convém às pessoas, remetendo à questão sobre quem pode e deve tomar as decisões. Uma concepção complexa da autonomia ressalta o seu caráter relacional, que implica na mediação entre saberes e experiências, pressupondo o reconhecimento do paciente como alguém capaz de questionamentos dignos de respostas. ${ }^{26}$ Requisita dos sujeitos envolvidos uma maior capacidade de articulação com as próprias demandas imaginárias que se conformam no contexto subjetivo do médico e do paciente. ${ }^{27} \mathrm{~A}$ autonomia do paciente é fundamental para o compromisso com a resolutividade, mas, no âmbito da biomedicina, Soares e Camargo 26 (2007:70) interrogam: "Como pensar em sujeitos autônomos, quando nem como pessoas esses doentes são considerados?"

A consulta em que foi designada a conduta reiterou a subordinação em relação ao médico, porém com diferenças importantes nos sentidos atribuídos à experiência. No Grupo 1, num contexto de confiança na competência e solicitude do profissional, a estratégia realista foi acompanhada por uma visão otimista das possibilidades terapêuticas, trazendo satisfação.

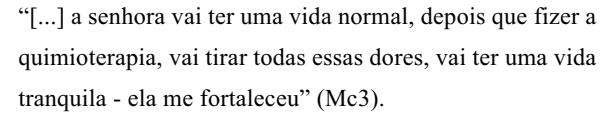

"[...] a senhora vai ter uma vida normal, depois que fizer a quimioterapia, vai tirar todas essas dores, vai ter uma vida tranquila - ela me fortaleceu" (Mc3).

A atitude das pacientes deste grupo indicou a possibilidade de considerarem "natural" os médicos decidirem isoladamente sobre o tratamento. Com base na concepção de Thompson 10 cabe argumentar que, talvez premidas pelo temor da morte, valorizaram a praticidade, assim, mais que outras, respeitando um saber-fazer superior que encontra alternativas para solucionar o problema. Esta é uma estratégia típica de valorização simbólica quando se ocupa uma posição subordinada dentro de um campo de interação. A praticidade pode caminhar junto à resignação respeitosa, explicitada por uma delas ao reconhecer como inevitável a aceitação da conduta orientada, dada à inferioridade do seu conhecimento.

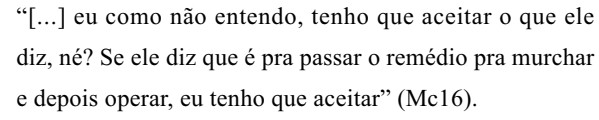

No Grupo 2, os relatos sugeriram que predominava o caráter burocrático da comunicação do resultado e tratamento. Muitas necessidades de informação ficaram insatisfeitas (resultado inconclusivo, conduta expectante, indicação cirúrgica), originando uma percepção de descaso e medo do agravamento. O significado do câncer alimentava temores diante do acompanhamento médico com resultado inconclusivo: "essa doença é muito traiçoeira... então eu sei que há essa possibilidade de depois eu estar com ela, mas hoje eu estou aliviada" (M6); e conclusivo: "eu encontrei uma senhora que tava com um centímetro, ela já perdeu a mama e fez até quimioterapia, eu vou esperar o quê?" (M13). Contudo, poucas questionaram: " $n$ ão é melhor a gente fazer outra (biópsia) não?” (M1).

Várias mulheres do Grupo 2 que discordaram da conduta médica mantiveram-se silenciosas diante do profissional, dizendo-se contrafeitas. Para Bensing et al.,11 até mesmo pacientes que manifestam preferência por maior participação, necessariamente, não adotam essa atitude na consulta. Poucas sinalizaram com a possibilidade de recorrer à rejeição, estratégia que, segundo Thompson, 10 é adotada por aqueles que ocupando uma posição subordinada, buscam uma maneira de afirmar sua discordância: "eu até 
pensei de trocar de médico" (M14). Essa atitude sugere uma maneira de afirmar os próprios pontos de vista sem romper com a distribuição desigual de poder, característica da comunicação profissionalcentrada.

No presente estudo, ao reproduzir a relação assimétrica ligada à dominação, parece que pacientes e profissionais não compreendem que não existe um que não sabe, mas dois que sabem coisas distintas. ${ }^{19}$ Para ampliar as possibilidades de auxílio, mediante um saber-fazer efetivo não somente contra a doença, mas para o doente, é essencial assumir que acolhimento e comunicação dialógica são inseparáveis. ${ }^{20}$ Compreendida como troca, a relação dialógica implica que os envolvidos estejam empenhados numa interação genuína, onde cada um deseja alcançar a compreensão dos significados atribuídos e dos sentimentos mobilizados pelo adoecimento. $5,6,27$

Para Teixeira20 (2003:105): "a arte da conversa não é homogeneizar os sentidos fazendo desaparecer as divergências, mas fazer emergir o sentido no ponto de convergência das diversidades". Dessa perspectiva, embora o paciente recorra à autoridade do conhecimento médico, a mesma não autoriza o profissional a tomar para si a iniciativa e a decisão.

Apesar da ampliação do predomínio de uma comunicação profissional-centrada, a literatura mostra que uma transformação se esboça no campo da comunicação entre médicos e portadores de câncer, conferindo às práticas de saúde um caráter de prática de conversação. Assim, ocorre o desenvolvimento, ainda incipiente, de uma comunicação pessoa-centrada, que traduz uma maior sensibilidade diante do sofrimento e favorece a expressão e o acolhimento de demandas e necessidades. ${ }^{11,18}$

\section{Considerações finais}

Numa situação crítica como o processo diagnóstico de nódulo mamário, que torna essencial uma atuação compreensiva, a comunicação médico-paciente teve caráter informativo e paternalista, com maior atenção sendo dada àquelas com suspeita de câncer. A qualidade das relações interpessoais é um elemento fundamental na consulta, que facilita a conversa informativa, mas não assegura reciprocidade na conversação. Assim, quase nunca foi considerado o direito da paciente de opinar sobre suas

\section{Referências}

1. Brasil. Ministério da Saúde. Instituto Nacional do Câncer. Estimativa 2012 - Síntese de resultados e comentários. conveniências, e nenhuma delas, ainda quando muito insatisfeitas, visaram de fato um projeto terapêutico individual. Dialogar é tarefa difícil para médicos e pacientes.

Os relatos indicaram um médico guiado por uma visão diagnóstica e terapêutica reduzida a protocolos cada vez mais padronizados, que facultava a realização de ajustes sempre na busca de "convencer" o outro de que estava com a razão. Essa forma de comunicação descontextualiza a ação e, desconsiderando que o sentido de uma situação é produzido pelo conjunto de visões de mundo, saberes e afetos, mantém o paciente ocupando uma posição "inferior" na hierarquia. Por outro lado, nos padrões de significados incorporados pelos pacientes, a expectativa de autoridade em relação ao médico pode facilitar desigualdade e imposição. O poder simbólico presente na relação hierarquizada entre médico e paciente não pode ser exercido sem a colaboração do paciente.

Ademais, numa prática em saúde fundada em evidências comprovadas pela ciência, a suspeita e o diagnóstico de câncer de mama fornecem uma base cientificamente definida da severidade do problema, legitimando o sofrimento do doente e a comunicação de informações tidas como necessárias pelo médico. Nesta pesquisa, a supervalorização da racionalidade técnica no processo saúde-doença-atenção dificultou o delineamento de limites e potencialidades dos padrões científicos, secundarizando a dimensão relacional, ética, do ato médico. Num contexto onde predominam os nódulos diagnosticados como benignos, despertam preocupação as repercussões desse modo de conceber e atuar no "acolhimento" e adesão às condutas.

Uma assistência qualificada requer valorização da dimensão comunicacional pelos pacientes, na formação médica e compromisso da gestão para que ocorram mudanças no trabalho. O médico necessita valorizar a compreensão dos contextos de vida e significado do adoecimento, mostrar-se aberto a acolher o sofrimento do outro e desenvolver habilidades comunicacionais (a escuta qualificada, diálogo e atenção às manifestações não verbais). Ele também precisa contar com apoio institucional para preservar sua saúde frente às possibilidades emocionais das relações humanas e desenvolver avaliação continuada de sua prática.

Disponível em: <http://www.inca. gov.br/estimativa/ 2012/index.asp?ID=5> Acesso em 05 mar. 2012. 
2. Júnior HSAC, Camargo MMA, Teixeira SRC, Arruda MS Biópsia de fragmento em nódulos mamários suspeitos com até $10 \mathrm{~mm}$. RevBrasGinecol Obstet. 2007; 29: 317-23.

3. Silva LC. Câncer de mama e sofrimento psicológico: aspectos relacionados ao feminino. Psicol Estud. 2008; 13: 231-7.

4. Bergamaso RB, Angelo M. O sofrimento de descobrir-se com câncer de mama: como o diagnóstico é experienciado pela mulher. Rev Bras Cancerol. 2001; 47: 277-82.

5. Ayres JRCM. Organização das ações de atenção à saúde: modelos e práticas. Saúde Soc. 2009; 18 (Supl. 2): 11-23.

6. Deslandes SF, Mitre RMA. Processo comunicativo e humanização em saúde. Interface Comun Saúde Educ. 2009; 13 (Supl. 1): 641-49.

7. Caprara A, Franco ALS. A relação médico-paciente: para uma humanização da prática médica. Cad Saúde Pública. 1999; 15: 647-54.

8. Guedes CR, Nogueira MI, Camargo Jr KR. A subjetividade como anomalia: contribuições epistemológicas para a crítica do modelo biomédico. Ciênc Saúde Coletiva. 2006; 11: 1093-103.

9. Schraiber LB. No encontro da técnica com a ética: o exercício de julgar e decidir no cotidiano do trabalho em medicina. Interface Comun Saúde Educ. 1997; 1: 123-40.

10. Thompson JB. Ideologia e cultura moderna: teoria crítica na era dos meios de comunicação de massa. 8 ed. Petrópolis, RJ: Vozes; 2009.

11. Bensing JM, Tromp F, Dulmen S, Brink-Muinen A, Verheul W, Schellevis FG. Shifts in doctor-patient communication between 1986 and 2002: a study of videotaped General Practice consultations with hypertension patients. BMC Family Practice. 2006; 7: 62.

12. Campos GWS. A mediação entre conhecimento e práticas sociais: a racionalidade da tecnologia leve, da práxis e da arte. Ciênc Saúde Coletiva. 2001; 16: 3033-40.

13. Parker PA, Aaron J, Baile WF. Breast cancer: unique communication challenges and strategies to address them. Breast J. 2009; 15: 69-75

14. Wright EB, Holcombre C, Salmom P. Doctors' communication of trust, care, and respect in breast cancer: qualitative study. BMJ. 2004; 328 (7444): 864.

15. Ha JF, Longnecker N. Doctor-patient communication: review. Ochsner J. 2010; 10: 38-43.

16. Fujimori M, Uchitomi Y. Preference of cancer patients regarding communication of bad news: a systematic literature review. J Clin Oncol. 2009; 39: 201-16

17. Diaz FG. Comunicando malas noticias en medicina: recomendaciones para hacer de la necesidad virtud. Med Intensiva. 2006; 30: 452-59.

\footnotetext{
Recebido em 8 de novembro de 2013

Versão final apresentada em 18 de julho de 2014

Aprovado em 19 de agosto de 2014
}

18. Back AL, Arnold RM. Discussing prognosis: "How much do you want to know?" Talking to patients who are prepared for explicit information. J Clin Oncol. 2006; 24: 4209-13.

19. Gadamer HG. O caráter oculto da saúde. Petrópolis (RJ): Vozes; 2006.

20. Teixeira RR. O acolhimento num serviço de saúde entendido como uma rede de conversações. In: Pinheiro R, Mattos RA. Construção da integralidade: cotidiano, saberes e práticas em saúde. Rio de Janeiro: UERJ, IMS: ABRASCO; 2003. p. 89-111.

21. Minayo MCS. O desafio do conhecimento: pesquisa qualitativa em saúde. $9^{a}$ edição. São Paulo: Hucitec; Rio de Janeiro: Abrasco; 2006

22. Gadamer HG. Verdade e Método: traços fundamentais de uma hermenêutica filosófica. $2^{\mathrm{a}}$ Edição. Petrópolis (RJ): Vozes; 1997.

23. Schraiber LB. O médico e suas interações: a crise dos vínculos de confiança. São Paulo: Aderaldo e Rothschild; 2008

24. Silva MJP. O papel da humanização na comunicação na humanização da atenção à saúde. Bioética. 2002; 10: 73-88.

25. Barry CA, Stevenson FA, Britten N, Barber N, Bradley CP. Giving voice to the lifeworld. More humane, more effective medical care? A qualitative study of doctor-patient communication in general practice. Soc Sci Med. 2001; 53: 487505

26. Soares JCRS, Camargo Jr KR. A autonomia do paciente no processo terapêutico como valor para a saúde. Interface Comun Saúde Educ. 2007; 21: 65-78.

27. Jorge MSB, Pinto DM, Quinderé PH, Pinto AGA, Sousa FSP, Cavalcante CM. Promoção da saúde mental: tecnologias do cuidado: vínculo, acolhimento, co-responsabilização e autonomia.Ciênc Saúde Coletiva. 2011; 16: 305160

28. Demir F, Donmez YC, Ozsaker E, Diralami A. Patients' lived experiences of excisional breast biopsy: a phenomenological study. J Clin Nurs.2008; 7: 744-51.

29. Longtin Y, Sax H, Leape LL, Sheridan SE, Donaldson L, Pittet D. Patient participation: current knowledge and applicability to patient safety. Mayo Clin Proc. 2010; 85: 53-62.

30. CFM (Conselho Federal de Medicina). Código de Ética Médica. [acesso em $28 \mathrm{dez}$ 2010]. Disponível em: $<$ http://www.portalmedico.org.br/ novocodigo/integra_4.asp > 